\title{
Erratum to: A New Approach on Color Image Encryption Using Arnold 4D Cat Map
}

Bidyut Jyoti Saha, Kunal Kumar Kabi and Chittaranjan Pradhan

\section{Erratum to:}

Chapter 'A New Approach on Color Image Encryption Using Arnold 4D Cat Map' in: H.S. Behera and D.P. Mohapatra (eds.), Computational Intelligence in Data Mining - Volume 1, Advances in Intelligent Systems and Computing 410, DOI 10.1007/978-81-322-2734-2_14

The original version of the book's chapter 'A New Approach on Color Image Encryption Using Arnold 4D Cat Map' was inadvertently published with an incorrect affiliation as 'Industrial and Financial Systems, Capgemini, Bhubaneshwar, India' whereas the correct affiliation is 'Industrial and Financial Systems, Capgemini, Mumbai, India'. The erratum chapter and the book has been updated with the correction.

The updated original online version for this chapter can be found at DOI 10.1007/978-81-322-2734-2_14

\author{
B.J. Saha ( $₫)$ \\ Industrial and Financial Systems, Capgemini, Mumbai, India \\ e-mail: bidyutjyotisaha@gmail.com \\ K.K. Kabi \\ Guidewire Practice, CGI, Bhubaneswar, India \\ e-mail: kunal.kabi90@gmail.com \\ C. Pradhan \\ School of Computer Engineering, KIIT University, Bhubaneshwar, India \\ e-mail: chitaprakash@gmail.com

